\title{
Synthesis and Catalytic and Biological Activities of Silver and Copper Nanoparticles Using Cassia occidentalis
}

\author{
Manjul Gondwal (iD and Geeta Joshi nee Pant $\mathbb{1}$ \\ Department of Chemistry, Hemvati Nandan Bahuguna Garhwal University, Srinagar, Garhwal, Uttarakhand, India \\ Correspondence should be addressed to Manjul Gondwal; m.gondwal@gmail.com
}

Received 25 December 2017; Revised 7 March 2018; Accepted 22 March 2018; Published 2 May 2018

Academic Editor: Vijaya Kumar Rangari

Copyright (c) 2018 Manjul Gondwal and Geeta Joshi nee Pant. This is an open access article distributed under the Creative Commons Attribution License, which permits unrestricted use, distribution, and reproduction in any medium, provided the original work is properly cited.

\begin{abstract}
An ecofriendly and green method for the synthesis of silver and copper nanoparticles has developed using aqueous leaves extract of Cassia occidentalis. The formation of AgNPs and CuNPs was monitored by measuring the UV-Vis spectra. The morphology and crystalline phase of the metal nanoparticles were determined using transmission electron microscopy (TEM) and scanning electron microscopy (SEM) with X-ray energy dispersive spectrophotometer (EDX) and X-ray diffraction (XRD). The synthesized metal nanoparticles were generally found to be spherical and oval in shape. The AgNPs and CuNPs showed highly potent antibacterial activity against Escherichia coli and Salmonella typhi bacteria, respectively. The CuNPs showed higher radical scavenging activity than AgNPs. The AgNPs showed lower haemolysis (1.7\%) exhibiting lesser toxicity as compared to CuNPs. The CuNPs have better catalytic ability for the reduction of 4-nitrophenol and 2-nitrophenol as compared to AgNPs.
\end{abstract}

\section{Introduction}

Metal nanoparticles have been studied for their remarkable optical and electronic properties and their applications in the areas such as optics, optoelectronics, catalysis, nanostructure fabrication, and chemical sensing [1]. The physical and chemical methods used for the synthesis of metal nanoparticles are expensive and potentially dangerous to the environment [2]. These methods have many drawbacks including use of toxic solvents, generation of hazardous byproducts, and high energy consumption. So, there is a need to develop environmentally benign procedures for synthesis of metal nanoparticles.

Metal nanoparticles (MNPs) such as silver and copper nanoparticles have been known to have inhibitory and bactericidal effects [3]. The most widely used known applications of silver metal and silver nanoparticles are in the medical industry. These include topical ointments and creams containing silver to prevent infection of burns and open wounds [4]. Copper nanoparticles have been used as disinfectants in water treatment plants, food processing, wound healing ointments, bandages, and so on because of their antibacterial as well as antiviral properties $[5,6]$.
Cassia occidentalis Linn. (Caesalpiniaceae) is a native plant of southern India, Burma, Sri Lanka, and scattered from foothills of Himalayas to West Bengal. It is used against fever, menstrual problems, and tuberculosis, as diuretic, in anaemia, in liver complaints, and as a tonic against general weakness and illness [7]. C. occidentalis leaf extracts exhibit antibacterial, antimalarial, anticarcinogenic, and hepatoprotective activity [8-10]. Chemical constituents isolated from $C$. occidentalis include sennoside, anthraquinone glycoside, fatty oils, flavonoid glycosides, galactomannan, polysaccharides, and tannins $[11,12]$.

Plant extract used in the green synthesis processes has received increasing attention for the development of metal nanoparticles [13]. The green synthesis techniques are generally synthetic routes that utilize relatively nontoxic chemicals to synthesize nanomaterials, and include the use of nontoxic solvents such as water, biological extracts, and microwave assisted synthesis. In the present paper, silver and copper nanoparticles were synthesized from leaves' extract of $C$. occidentalis and characterized by various spectroscopic techniques and examined for antibacterial, antioxidant activity and for toxicity. Further, these nanoparticles were employed as catalysts in the reduction of nitro compounds. 


\section{Experimental Section}

2.1. Reagents and Materials. Silver nitrate $\left(\mathrm{AgNO}_{3}\right)$, cupric nitrate $\left(\mathrm{Cu}\left(\mathrm{NO}_{3}\right)_{2}\right)$, and nitrophenols were obtained from Merck Chemicals. All glassware has been properly washed with distilled water and dried in oven before use.

2.2. Green Synthesis of Silver Nanoparticles. Fresh leaves of $C$. occidentalis were collected from Garhwal University campus in the month of April. They were washed with distilled water and air-dried at room temperature. The $10 \mathrm{gm}$ of leaves was kept in a beaker containing $100 \mathrm{ml}$ deionized water and boiled for $30 \mathrm{~min}$. The extract was cooled down and filtered with Whatman filter paper no. 1 and extract was stored in a refrigerator at $4^{\circ} \mathrm{C}$.

The silver nanoparticles were synthesized by treating the freshly prepared $1 \mathrm{mM}$ silver nitrate and stored under dark conditions with aqueous extract of the plant. The reaction mixture was prepared in a ratio of 9:1 (V/V) comprised of freshly prepared silver nitrate solution and plant extract, respectively [14]. The solution was stored at room temperature for 24 hours for the complete settlement of nanoparticles. After 24 hours the reaction mixture was centrifuged at $5000 \mathrm{rpm}$ for 15 minutes and pellets were collected followed by washing with deionized water and dried in watch glass at room temperature. The resulting dried product was crushed into powder and stored in air tight container for further analysis.

2.3. Green Synthesis of Copper Nanoparticles. The $10 \mathrm{gm}$ of leaves was boiled with $100 \mathrm{ml}$ deionized water for $30 \mathrm{~min}$. The extract was cooled down and filtered with Whatman filter paper no. 1 and extract was stored in a refrigerator at $4^{\circ} \mathrm{C}$. The CuNPs were prepared by adding $10 \mathrm{ml}$ of aqueous extract of plant material to $50 \mathrm{ml}$ of $1 \mathrm{mM}$ aqueous solution of cupric nitrate [15]. The mixture was irradiated in microwave oven for 4 hours and allowed to cool at room temperature. Finally, the reaction mixture was centrifuged at $5000 \mathrm{rpm}$ for 15 minutes and residue was dried at room temperature.

2.4. Characterization Techniques. The formation of metal nanoparticles was confirmed by monitoring the reaction mixture at regular intervals (5 min, $10 \mathrm{~min}, 15 \mathrm{~min}, 30 \mathrm{~min}, 1-$ hour, 2-hour, 4-hour, and 24-hour for AgNPs and 1-hour, 2hour, 3-hour, and 4-hour for CuNPs). When the reaction was carried out, during the course of the reaction small amount of aliquot in between some time intervals was withdrawn and dissolved in $3 \mathrm{ml}$ of distilled water and the absorption maximum was scanned by UV-Visible spectra, in a range of wavelength between 200 and $800 \mathrm{~nm}$ using UV-Visible Perkin Elmer Lambda 25. Fourier transform infrared (FTIR) spectra of the MNPs were recorded using a Lambda Scientific FTIR-7600 instrument with $\mathrm{KBr}$ pellet technique in the range $400-4000 \mathrm{~cm}^{-1}$. The particle size, crystal structure, and phase identification of the metal nanoparticles were determined using XRD PW3040/60 X-pert PRO (Netherlands), operating at a voltage of $45 \mathrm{kV}$ and a current of $40 \mathrm{~mA}$ with $\mathrm{Cu}$ $\mathrm{K} \alpha$ radiation at $2 \theta$ angle ranging from $20^{\circ}$ to $90^{\circ}$. SEM (Scanning Electron Microscope, JEOL JSM 5600) was used to observe the surface topographies of metal nanoparticles and the elemental analysis was carried out to confirm the presence of metallic silver and copper in the reaction mixture by recording EDX. The morphology and size of the metal nanoparticles were studied by transmission electron microscopy (TEM) analysis using Tecnai $20 \mathrm{G}^{2}$ instrument.

2.5. Antibacterial Activity. Synthesized silver and copper nanoparticles were tested for antimicrobial activity by disc diffusion method against pathogenic bacteria Staphylococcus aureus, Salmonella typhi, Escherichia coli, and Klebsiella pneumonia [16]. The sterilized discs were dipped in different concentrations of metal nanoparticles dispersion in dimethyl sulphoxide (DMSO), namely, 100\% (10 $\mu \mathrm{g} / \mathrm{ml}), 75 \%$ $(7.5 \mu \mathrm{g} / \mathrm{ml})$, and $50 \%(5.0 \mu \mathrm{g} / \mathrm{ml})$, and dried in an oven at $30-40^{\circ} \mathrm{C}$. The metal nanoparticles impregnated discs were placed on the plates and kept for incubation at $37^{\circ} \mathrm{C}$ for 24 hours. After incubation, the different levels of zone of inhibition of bacteria were measured. The standard antibiotic drugs ciprofloxacin and gentamycin were used as reference and 10\% DMSO was used as control. The experiments were done in triplicate and mean values of zone diameter were taken.

2.6. Haemolytic Activity. In order to know the toxicity of synthesized metal nanoparticles, the hemolysis assay was performed of the silver and copper nanoparticles with acid citrate dextrose (ACD) human blood. Equal weights of silver and copper nanoparticles were taken in different test tubes and $10 \mathrm{~mL}$ of phosphate buffer solution was added. Positive and negative controls were produced by adding $0.2 \mathrm{ml}$ of human blood to $4 \mathrm{ml}$ of distilled water and $10 \mathrm{~mL}$ PBS solution, respectively. All these test tubes were kept in desiccators for $30 \mathrm{~min}$ at $37^{\circ} \mathrm{C}$ and $0.2 \mathrm{~mL}$ of ACD blood was added to each test tube and the test tubes were kept for $1 \mathrm{~h}$ in incubator at $37^{\circ} \mathrm{C}$. The test tubes were centrifuged at $4500 \mathrm{rpm}$ for $8 \mathrm{~min}$. Optical density (OD) of silver and copper nanoparticles, positive and negative control treated samples, was calculated at $545 \mathrm{~nm}$ from $1 \mathrm{~mL}$ supernatant [17]

$$
\begin{aligned}
& \% \text { of hemolysis } \\
& =\frac{\text { OD of the sample }- \text { OD of the negative control }}{\text { OD of the positive control - OD of the negative control }} \\
& \quad \times 100,
\end{aligned}
$$

where OD of the sample is the optical density of the sample, OD of the negative control is the optical density of the phosphate buffer saline, and OD of the positive control is the optical density of the water.

2.7. Antioxidant Activity. The metal nanoparticles were screened for free radical scavenging activity by DPPH method [18]. The AgNPs and CuNPs dispersed in methanol $(10-100 \mu \mathrm{g} / \mathrm{ml})$ were added to different test tubes and the volume was made up to $4 \mathrm{ml}$ using methanol, separately. Then, $3 \mathrm{ml}$ of DPPH $(0.1 \mathrm{mM})$ solution was added and incubated in a dark room for about $30 \mathrm{~min}$ at room temperature. All the solution was prepared in the laminar flow. The scavenging activity on the DPPH radical was determined by measuring 
the absorbance at $517 \mathrm{~nm}$ against a blank with an ultravioletvisible spectrophotometer. Gallic acid and BHT were used as positive control. Tests were performed in triplicate and the results were averaged

$$
\begin{gathered}
\% \text { of radical scavenging activity } \\
=\left[A_{\text {control }}-\frac{A_{\text {sample }}}{A_{\text {control }}}\right] \times 100,
\end{gathered}
$$

where $A_{\text {control }}$ is the absorbance of the control sample (DPPH solution without sample) and $A_{\text {sample }}$ is the absorbance of the sample (DPPH solution and sample).

2.8. Catalytic Activity. The synthesized metal nanoparticles were used as catalyst for the reduction of nitro compounds, that is, 4-nitrophenol and 2-nitrophenol to amino compounds by sodium borohydride [19]. To a $3 \mathrm{ml}$ cuvette containing freshly prepared sodium borohydride $(1 \mathrm{ml}, 0.2 \mathrm{M})$ solution, 4-nitrophenol ( $1.9 \mathrm{ml}, 0.2 \mathrm{mM})$ solution was added. The cuvette was then placed in a UV-Vis spectrophotometer and the absorbance against wavelengths recorded. After adding metal nanoparticles $(0.1 \mathrm{ml}, 0.1 \%)$ solution, the $\mathrm{cu}-$ vette was shaken vigorously for mixing and kept in a UV-Vis spectrophotometer and scanned from 200 to $800 \mathrm{~nm}$ ranges.

\section{Results and Discussion}

3.1. UV-VIS Spectroscopic Analysis. The UV-Vis absorption spectra of AgNPs and CuNPs prepared from leaves extract of C. occidentalis are shown in Figure 1. The absorption band of AgNPs occurs at $461.02 \mathrm{~nm}$. The AgNPs exhibit a yellowishbrown color in aqueous solution due to the excitation in UV-visible spectrum depending upon the particle size [20]. The absorption band of CuNPs occurs at $544.89 \mathrm{~nm}$. The absorption bands for CuNPs have been reported to be in the range of 500-600 $\mathrm{nm}$ [21]. The absorption peak ascribed to the SPR of Cu particles formed here [22]. The intensity of peak increases as a function of time in both the cases.

3.2. FTIR Analysis. The FTIR spectra were carried out to identify the possible biomolecules responsible for capping and reducing agent for the formation of metal nanoparticles. In Figure 2, FTIR spectra of silver and copper nanoparticles show strong absorption band at $1603 \mathrm{~cm}^{-1}$ and $1616 \mathrm{~cm}^{-1}$, respectively, and it is attributed to binding of $\mathrm{NHC}=\mathrm{O}$ to metal ions. Other peaks include $2922 \mathrm{~cm}^{-1}$ (secondary amine), $1383 \mathrm{~cm}^{-1}$ (C-N stretching vibration of aromatic amine), $1138 \mathrm{~cm}^{-1}, 821 \mathrm{~cm}^{-1}, 764 \mathrm{~cm}^{-1}$, and $595 \mathrm{~cm}^{-1}$ for silver nanoparticles and $1383 \mathrm{~cm}^{-1}, 1074 \mathrm{~cm}^{-1}$, and $601 \mathrm{~cm}^{-1}$ for copper nanoparticles. The presence of peak at $3186 \mathrm{~cm}^{-1}$ and $3341 \mathrm{~cm}^{-1}$ could be due to $\mathrm{O}-\mathrm{H}$ group in polyphenols or proteins or polysaccharide $[23,24]$. It has been reported that proteins can bind to metal nanoparticles through the free amine groups or carboxylate ion of amino acid residues. The phytochemical analysis of Cassia occidentalis has indicated the presence of phenolic compounds such as apigenin, emodin, aloe-emodin, rhein, and vitexin, which are responsible for the formation of metal nanoparticles (Figure 3) [11].
TABLE 1: Peak indexing from $d$-spacing for AgNPs using C. occidentalis.

\begin{tabular}{lccccc}
\hline SI number & $2 \theta$ & $d$-spacing & $1000 / d^{2}$ & $\left(1000 / d^{2}\right) / 60.04$ & $H k l$ \\
\hline 1. & 38.381 & 2.34 & 182.62 & 3 & 111 \\
2. & 44.481 & 2.03 & 242.66 & 4 & 200 \\
3. & 64.664 & 1.44 & 482.22 & 8 & 220 \\
4. & 77.561 & 1.22 & 671.86 & 11 & 311 \\
5. & 81.665 & 1.17 & 730.51 & 12 & 222 \\
\hline
\end{tabular}

TABle 2: Peak indexing from $d$-spacing for CuNPs using C. occidentalis.

\begin{tabular}{lccccc}
\hline SI number & $2 \theta$ & $d$-spacing & $1000 / d^{2}$ & $\left(1000 / d^{2}\right) / 74.11$ & $H k l$ \\
\hline 1. & 43.389 & 2.08 & 231.13 & 3 & 111 \\
2. & 50.352 & 1.81 & 305.24 & 4 & 200 \\
3. & 74.115 & 1.27 & 620.00 & 8 & 220 \\
\hline
\end{tabular}

3.3. X-Ray Diffraction Analysis. The powder XRD of the metal nanoparticles is recorded between $2 \theta$ values $20^{\circ}$ and $90^{\circ}$ and exhibits crystalline nature and is consistent with earlier reports showing possible peaks of silver and copper metal in Figure $4[15,25]$. Bragg's diffraction peaks for silver nanoparticles are observed at $38.38^{\circ}, 44.48^{\circ}, 64.66^{\circ}, 77.56^{\circ}$, and $81.66^{\circ}$ corresponding to $111,200,220,311$, and 222 , respectively, representing face centered cubic structure of silver. Bragg's reflections for copper nanoparticles are observed in XRD pattern with value of $43.6^{\circ}, 50.7^{\circ}$, and $74.45^{\circ}$ representing 111 , 200 , and 220 planes of FCC structure of copper. The average crystallite size of AgNPs and CuNPs was calculated to be about $31 \mathrm{~nm}$ and $26 \mathrm{~nm}$, respectively, using Scherer formula, $D=0.94 \lambda / \beta \cos \theta$, where $\lambda$ is incident $\mathrm{X}$-ray wavelength $(\mathrm{Cu}$ $\mathrm{K} \alpha=1.542 \AA$ ), $\beta$ is full width half maximum in radians of the prominent line, that is, (111), and $\theta$ is position of that line in the pattern.

3.3.1. Peak Indexing. The miller indices $(h k l)$ were calculated using $d$-spacing values and each peak of the powder diffraction pattern is assigned [26]. The data are given in Tables 1 and 2.

3.3.2. Crystallite Size Calculation. The average crystallite size has been calculated by using Debye-Scherrer formula [27, 28]. The calculated crystallite size details are in Tables 3 and 4.

3.4. SEM Analysis. The surface morphological and nanostructural studies using SEM are shown in Figure 5. The SEM micrographs clearly show well aggregates of silver nanoparticles of $C$. occidentalis with average particle sizes ranging from 20 to $65 \mathrm{~nm}$ and copper nanoparticles with $30-65 \mathrm{~nm}$ in size.

3.5. EDX Analysis. Figure 6 shows the elemental profile of synthesized silver and copper nanoparticles using leaves extract of C. occidentalis. The EDX analysis of silver nanoparticles shows an intense signal at $3 \mathrm{keV}$ indicating the presence 


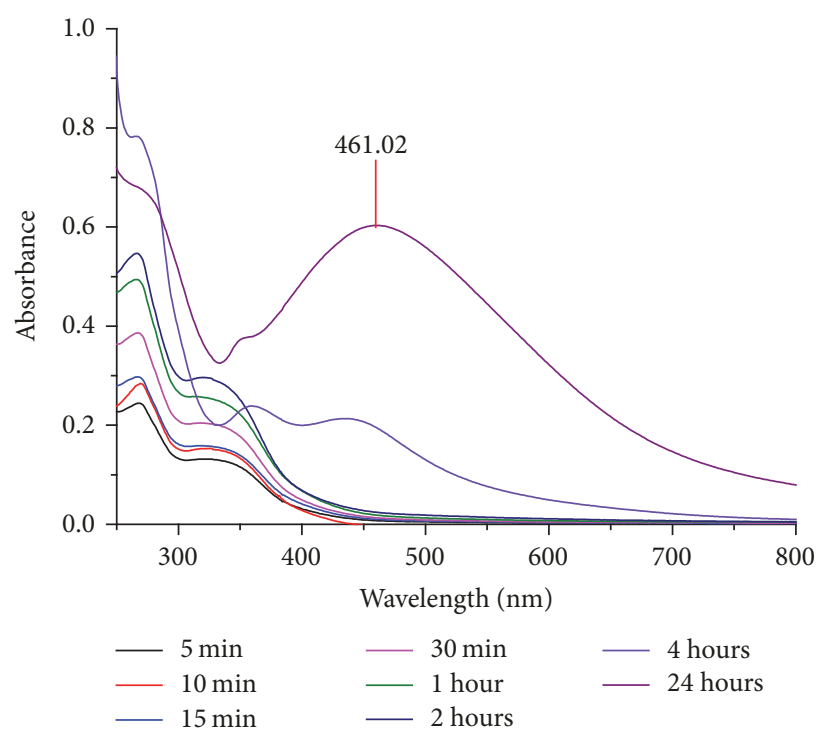

(a)

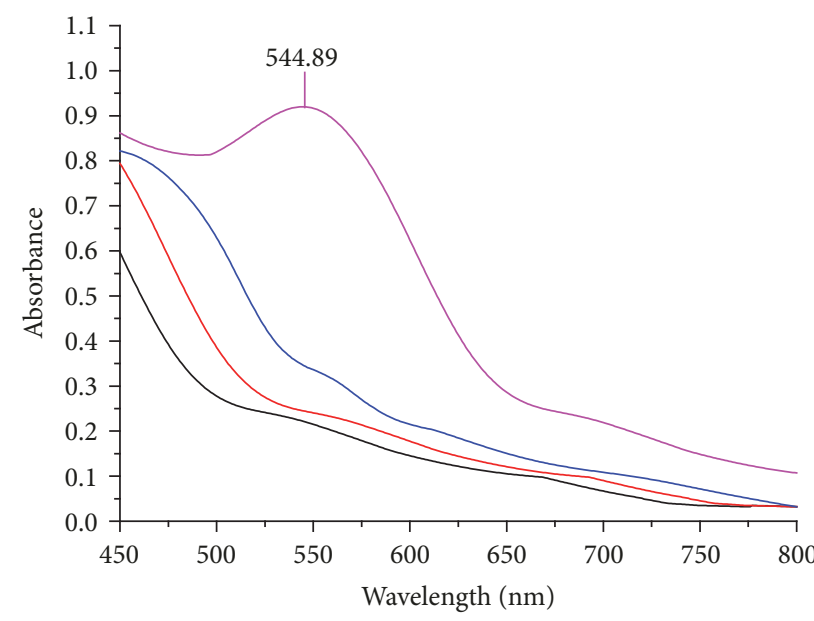

1 hour
-2 hours
-3 hours

(b)

FIgURE 1: UV-Vis absorption spectra of synthesized (a) AgNPs and (b) CuNPs.

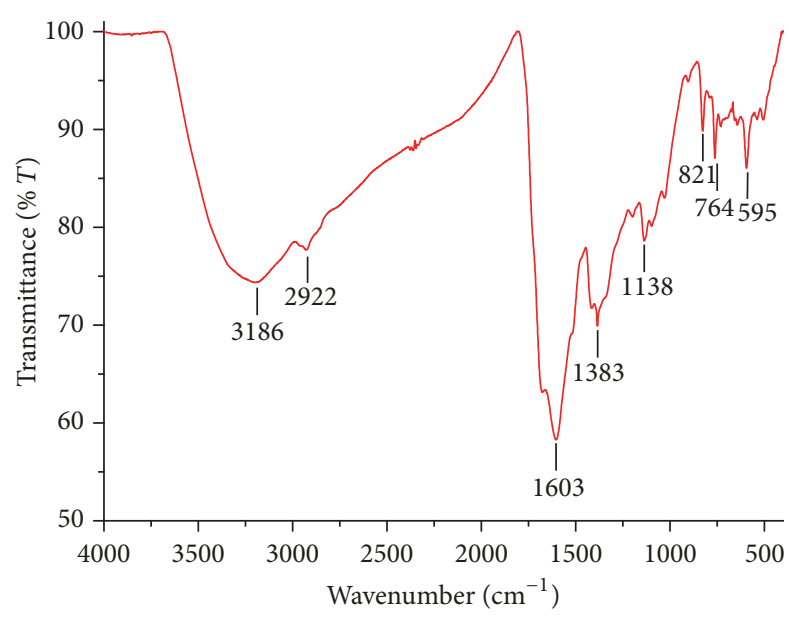

(a)

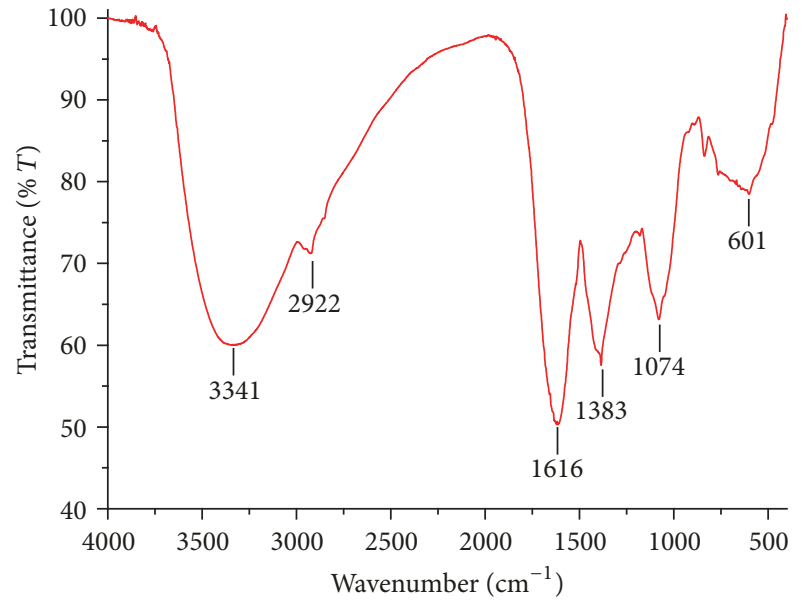

(b)

FIgURE 2: FTIR spectra of synthesized (a) AgNPs and (b) CuNPs.

TABLE 3: The crystallite size of AgNPs synthesized using C. occidentalis.

\begin{tabular}{lccc}
\hline $\begin{array}{l}\text { SI } \\
\text { number }\end{array}$ & $2 \theta$ value (degree) & FWHM (degree) & Crystallite size (nm) \\
\hline 1. & 38.381 & 0.5936 & 25.83 \\
2. & 44.481 & 0.7204 & 21.71 \\
3. & 64.664 & 0.4891 & 35.04 \\
4. & 77.561 & 0.6183 & 30.04 \\
5. & 81.665 & 0.4361 & 43.88 \\
\hline
\end{tabular}

of elemental silver in examined samples. The elemental analysis of the silver nanoparticles shown in the figure revealed a strong silver signal (66.43\%) along with weak signals of $\mathrm{O}$
TABLE 4: The crystallite size of CuNPs synthesized using C. occidentalis.

\begin{tabular}{lccc}
\hline $\begin{array}{l}\text { SI } \\
\text { number }\end{array}$ & $2 \theta$ value (degree) & FWHM (degree) & Crystallite size (nm) \\
\hline 1. & 43.389 & 0.5839 & 26.69 \\
2. & 50.524 & 0.8998 & 17.79 \\
3. & 74.115 & 0.7767 & 23.36 \\
\hline
\end{tabular}

(22.22\%) and $\mathrm{Cl}(8.12 \%)$. Furthermore, two small peaks of $\mathrm{Si}$ (1.67\%) and $\mathrm{Al}(1.56 \%)$ were also observed in the examined sample. The EDX analysis of copper nanoparticles possesses metallic copper (19.09\%) with some other impurities, that is, $\mathrm{O}(74.32 \%)$ and $\mathrm{Si}(6.59 \%)$. This includes elemental peaks at $1.00,8.00$, and $9.00 \mathrm{keV}$ for copper. 
<smiles>O=c1cc(-c2ccc(O)cc2)oc2cc(O)cc(O)c12</smiles>

(a)<smiles>O=C1c2cccc(O)c2C(=O)C2C(O)=CC(CO)=CC12</smiles>

(b)<smiles>CC1=CC2C(=O)c3cc(O)cc(O)c3C(=O)C2C(O)=C1</smiles>

(c)<smiles>O=C(O)C1=CC2C(=O)c3cccc(O)c3C(=O)C2C(O)=C1</smiles>

(d)<smiles>[14CH3]c1c(O)cc(O)c2c(=O)cc(-c3ccc(O)cc3)oc12</smiles>

(e)

Figure 3: Structure of (a) apigenin, (b) emodin, (c) aloe-emodin, (d) rhein, and (e) vitexin.

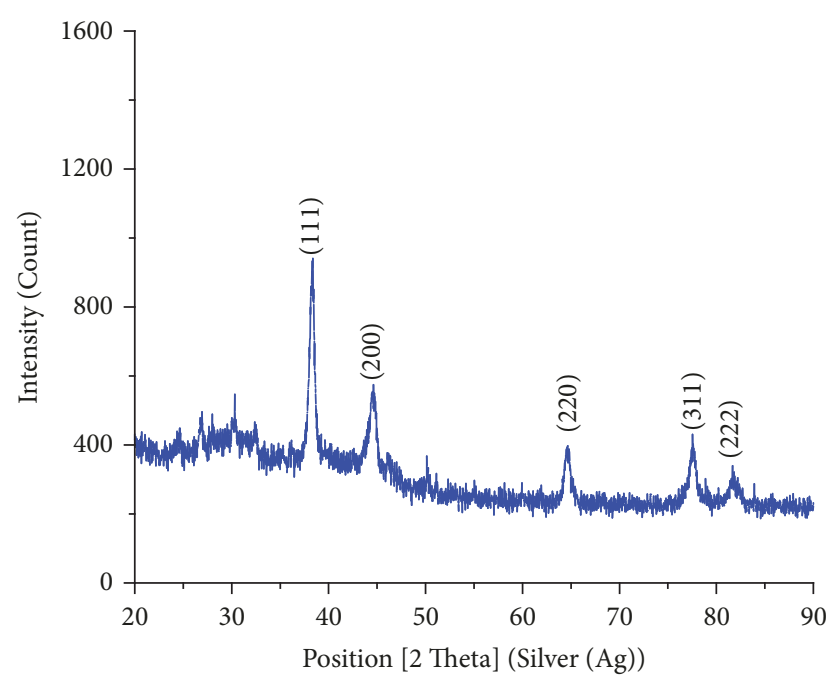

(a)

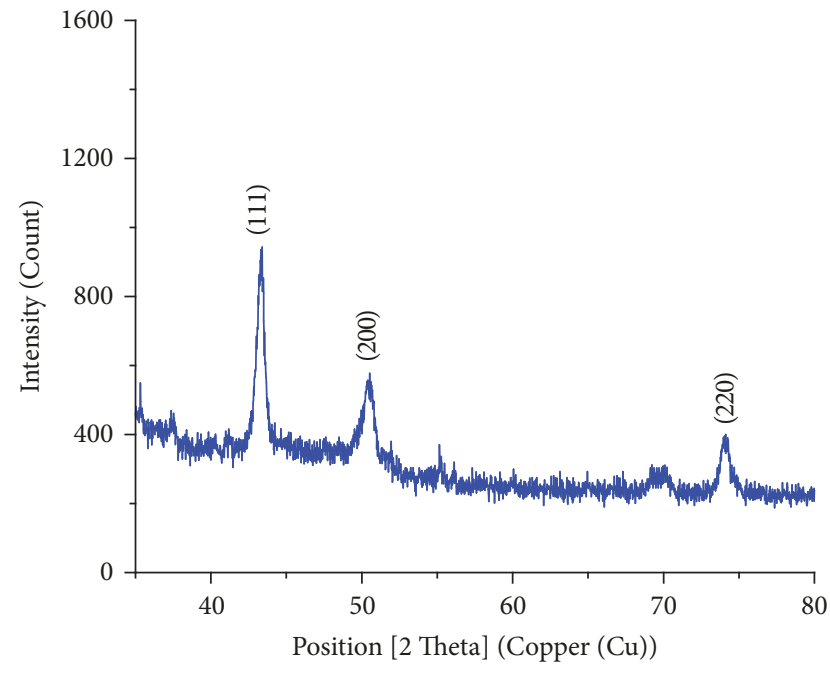

(b)

Figure 4: XRD spectrum of synthesized (a) AgNPs (b) CuNPs.

3.6. TEM Analysis. TEM micrograph shown in Figures 7 and 8 revealed that the particles are spherical, oval, and well dispersed. The particle size of synthesized AgNPs and CuNPs is in the range of 5-25 $\mathrm{nm}$ and 5-30 nm, respectively. Figure 9 shows the histogram of AgNPs and CuNPs of C. occidentalis, respectively. It is evident that there is variation in particle sizes.

3.7. Antibacterial Activity. Recently, silver and copper nanoparticles were found to be biocidal and as an antimicrobial coating on consumer products [29]. Research reports were available for using silver nanoparticles as antimicrobial agent against Gram positive strains (S. aureus and S. epidermidis) and Gram negative strains (E. coli, S. typhi, Pseudomonas aeruginosa, K. pneumoniae, and Proteus vulgaris) [30, 31]. Antimicrobial activity of AgNPs, CuNPs, and standards was tested by disc diffusion method against pathogenic bacteria. Both the particles have similar solubility and were soluble in dimethyl sulphoxide (control) and the zone of inhibition for control was $0(\mathrm{~mm})$. The activity of MNPs was concentration dependent against tested human pathogens. Antimicrobial activities increased with higher concentration of MNPs, $50 \%<75 \%<100 \%$. The zone of inhibition increases with increasing the concentration of MNPs [32]. Table 5 summarizes the antibacterial activity of MNPs. The biocapped AgNPs displayed higher antibacterial activity against E. coli and CuNPs were more effective against S. typhi.

3.8. Haemolytic Activity. The haemolytic activity of the silver and copper nanoparticles from $C$. occidentalis was tested against normal human erythrocytes. Haemolytic activity of the MNPs is expressed in percentage haemolysis and reported as mean \pm standard deviation of three replicates (Table 6 ). The toxicity of metal nanoparticles was checked by haemolysis. Haemolysis takes place when the red blood cells come in contact with water and it is important to check this implant 


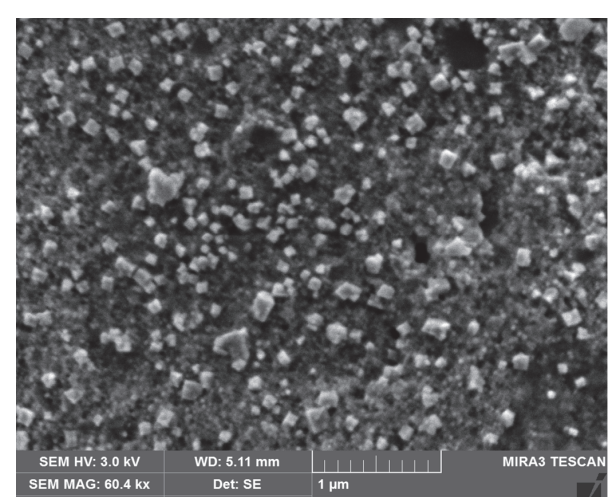

(a)

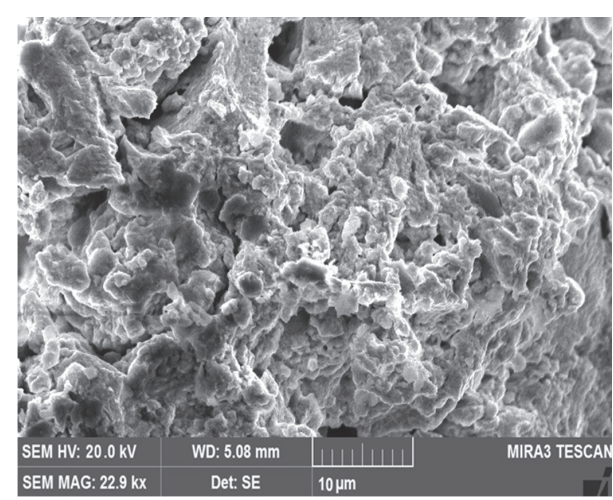

(b)

Figure 5: SEM micrograph of synthesized (a) AgNPs and (b) CuNPs.

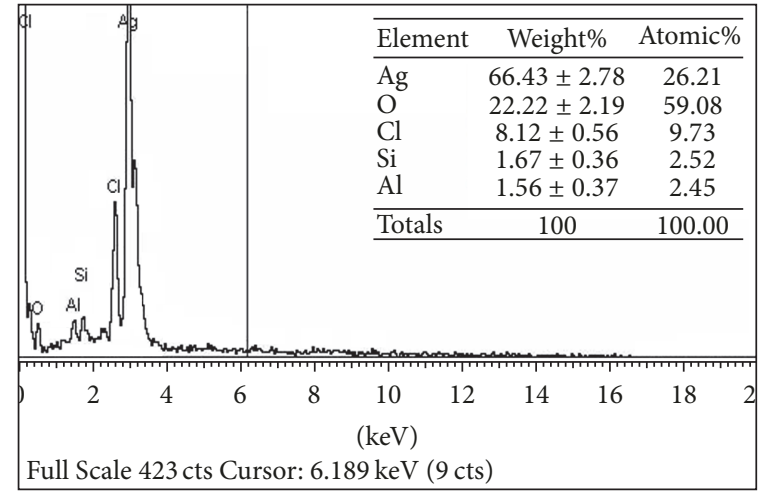

(a)

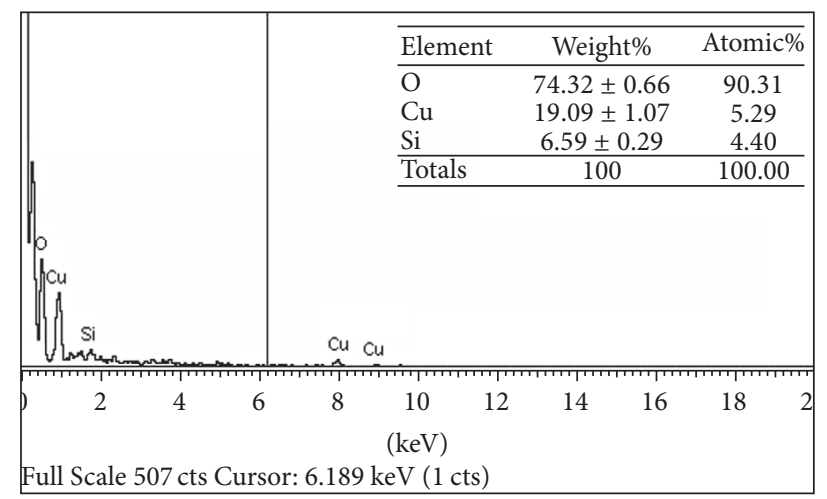

(b)

FIGURE 6: EDX spectrum of synthesized (a) AgNPs and (b) CuNPs.

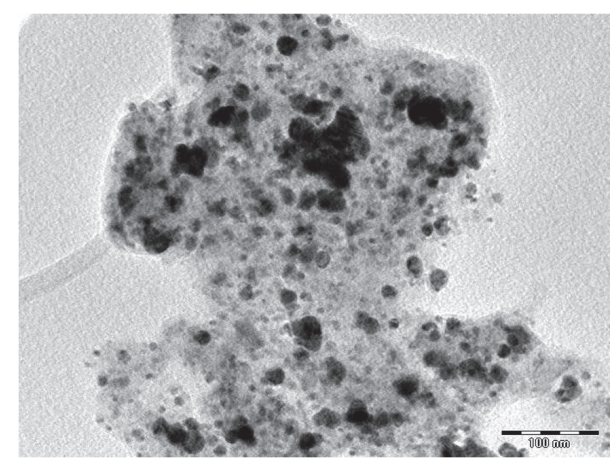

(a)

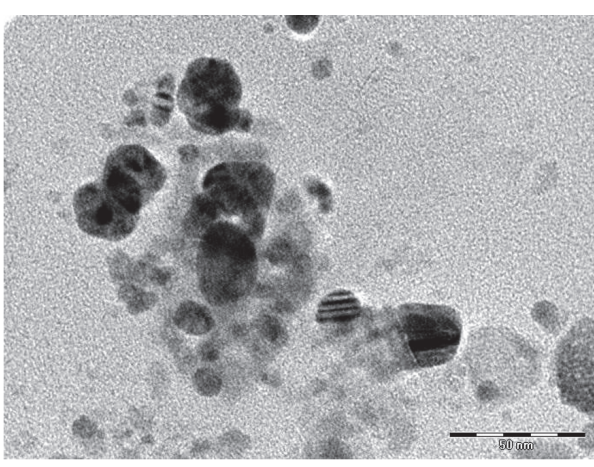

(b)

FIgURe 7: TEM micrograph of the AgNPs using C. occidentalis at the scale bar corresponds to (a) $100 \mathrm{~nm}$ and (b) $50 \mathrm{~nm}$.

TABLe 5: Antibacterial activity of AgNPs and CuNPs of C. occidentalis.

\begin{tabular}{|c|c|c|c|c|c|c|c|c|}
\hline \multirow{3}{*}{ Bacteria } & \multicolumn{8}{|c|}{ Zone of inhibition (mm) } \\
\hline & \multicolumn{3}{|c|}{ AgNPs } & \multicolumn{3}{|c|}{ CuNPs } & \multirow{2}{*}{ Ciprofloxacin (std.) } & \multirow{2}{*}{ Gentamycin (std.) } \\
\hline & $100 \%$ & $75 \%$ & $50 \%$ & $100 \%$ & $75 \%$ & $50 \%$ & & \\
\hline S. aureus & $10 \pm 0.5$ & $6 \pm 0.5$ & 0 & $10 \pm 0.5$ & $5 \pm 0.5$ & 0 & $15 \pm 0.5$ & $19 \pm 0.5$ \\
\hline E. coli & $13 \pm 0.5$ & $12 \pm 0.5$ & $10 \pm 0.5$ & $11 \pm 0.5$ & $8 \pm 0.5$ & $5 \pm 0.2$ & $20 \pm 0.5$ & $20 \pm 0.5$ \\
\hline S. typhi & $10 \pm 0.6$ & $9 \pm 0.2$ & $7 \pm 0.5$ & $12 \pm 0.5$ & $11 \pm 0.5$ & 0 & $21 \pm 0.5$ & $18 \pm 0.5$ \\
\hline K. pneumonia & $11 \pm 0.5$ & $10 \pm 0.2$ & 0 & $11 \pm 0.5$ & $9 \pm 0.5$ & $7 \pm 0.5$ & $19 \pm 0.5$ & $21 \pm 0.5$ \\
\hline
\end{tabular}




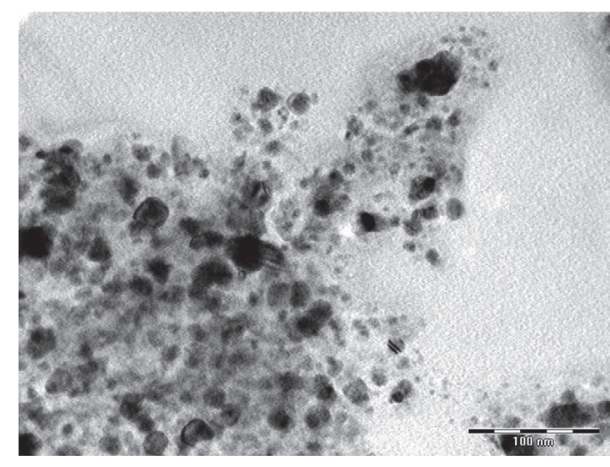

(a)

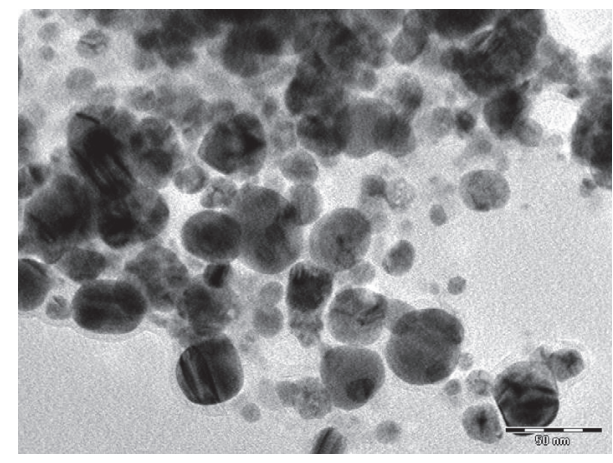

(b)

FIgURE 8: TEM micrograph of the CuNPs using C. occidentalis at the scale bar corresponds to (a) $100 \mathrm{~nm}$ and (b) $50 \mathrm{~nm}$.

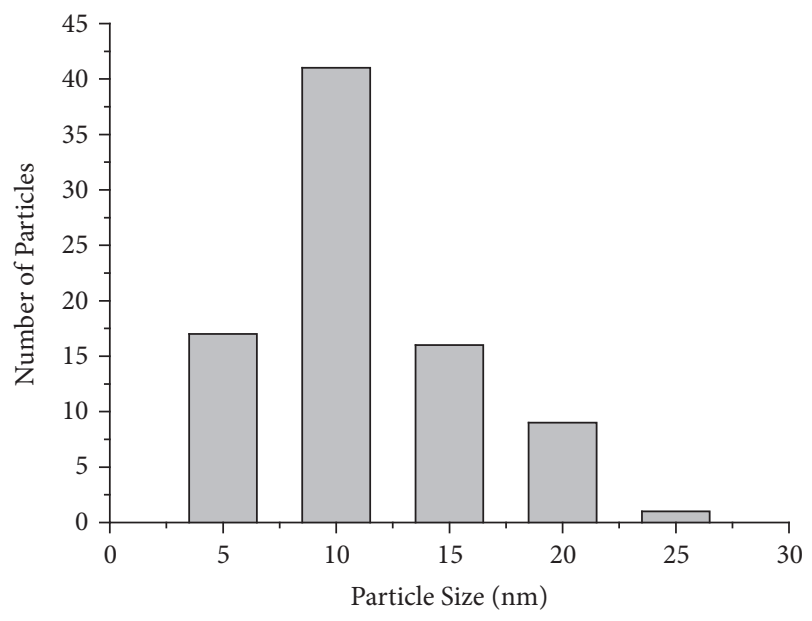

(a)

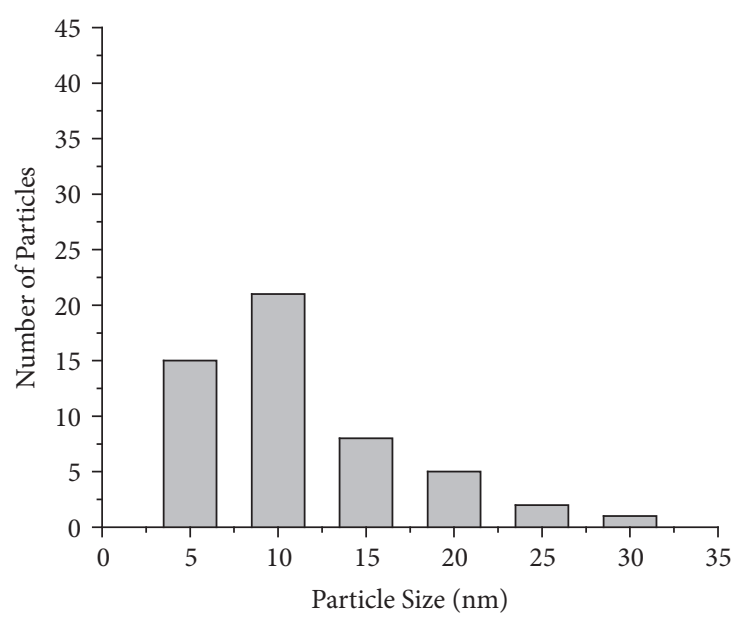

(b)

Figure 9: Particle size histogram of (a) AgNPs and (b) CuNPs at the scale bar corresponds to $100 \mathrm{~nm}$.

material before use. It has been well documented that the permissible limit of haemolysis for biomedical materials should be less than $5 \%$ in all the cases [33]. Haemolysis percentage of ACD blood with silver and copper nanoparticles was $1.7 \%$ and $4.6 \%$, respectively. Interestingly, silver nanoparticles show even lower haemolysis (1.7\%) exhibiting lesser toxicity as compared to copper nanoparticles.

3.9. Antioxidant Property. DPPH is a stable free radical scavenger and shows a characteristic absorption at $517 \mathrm{~nm}$ wavelength and after reduction color changes from violet to yellow [34]. The antioxidants react with DPPH and convert it to 1,1diphenyl-2-picryl hydrazine with decolorisation. The CuNPs showed higher free radical scavenging power than AgNPs and plant extract (Figure 10). The free radical scavenging activity of AgNPs at higher concentration $(100 \mu \mathrm{g} / \mathrm{ml})$ was found to be higher than plant extract. It was found that the $\mathrm{IC}_{50}$ value for AgNPs, CuNPs, and plant extract was $69.10 \mu \mathrm{g} / \mathrm{ml}$, $28.99 \mu \mathrm{g} / \mathrm{ml}$, and $65.94 \mu \mathrm{g} / \mathrm{ml}$, respectively. This is due to
TABLE 6: Haemolytic activity of synthesized silver and copper nanoparticles.

\begin{tabular}{lccc}
\hline $\begin{array}{l}\text { SI } \\
\text { number }\end{array}$ & $\begin{array}{c}\text { Metal } \\
\text { nanoparticles } \\
(\mathrm{MNPs})\end{array}$ & $\begin{array}{c}\text { Optical density } \\
(\mathrm{OD})\end{array}$ & $\begin{array}{c}\text { Haemolysis } \\
\text { percentage (\%) }\end{array}$ \\
\hline 1. & AgNPs & $0.078 \pm 0.001$ & $1.7 \%$ \\
2. & CuNPs & $0.130 \pm 0.005$ & $4.6 \%$ \\
3. & Negative sample & 0.048 & \\
4. & Positive sample & 1.836 & \\
\hline
\end{tabular}

the efficient oxidation of CuNPs $\left(\mathrm{Cu}^{0}+\mathrm{DPPH} \rightarrow \mathrm{Cu}^{2+}+\right.$ 1,1-diphenyl-2-picryl hydrazine). The CuNPs quenched the activity of DPPH by donating copper's electrons.

3.10. Catalytic Activity. The reduction of 4-nitrophenol (4$\mathrm{NP}$ ) and 2-nitrophenol (2-NP) was studied using $\mathrm{NaBH}_{4}$ in the presence of synthesized AgNPs and CuNPs using 


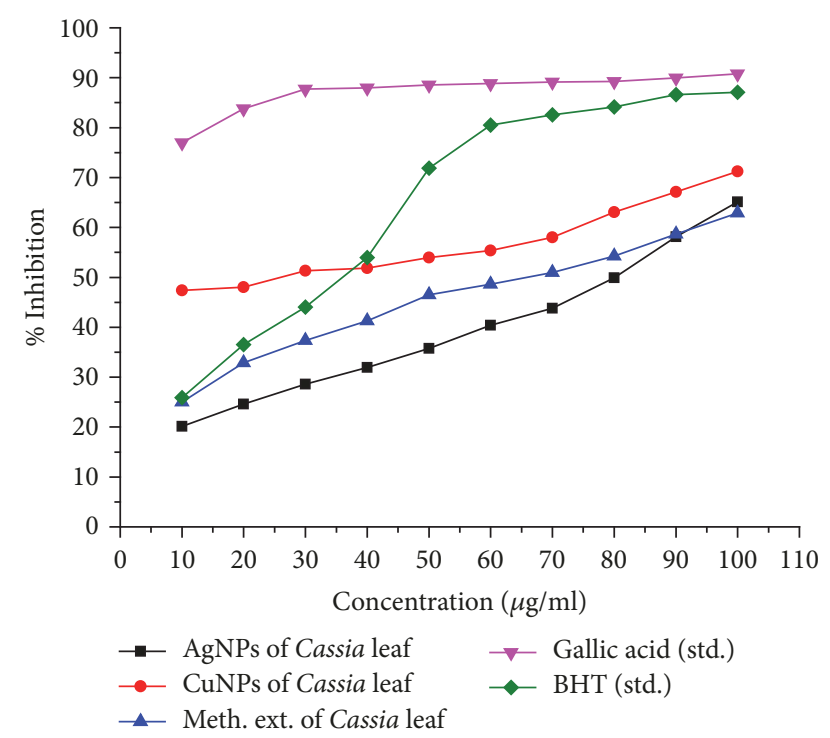

FIgURE 10: Antioxidant property of AgNPs and CuNPs using leaves extract of C. occidentalis.

C. occidentalis at room temperature and monitored by UVVisible spectroscopy $[19,35]$. The reduction of 4-NP to 4aminophenol (4-AP) using aqueous $\mathrm{NaBH}_{4}$ is thermodynamically favorable $\left(\mathrm{E}_{0}\right.$ for $4-\mathrm{NP} / 4-\mathrm{AP}=0.76 \mathrm{~V}$ and $\mathrm{H}_{3} \mathrm{BO}_{3} / \mathrm{BH}_{4}{ }^{-}$ $=1.33 \mathrm{~V}$ versus $\mathrm{NHE}$ ), but the presence of the kinetic barrier due to large potential difference between donor and acceptor molecules decreases the feasibility of this reaction. The MNPs catalyze this reaction by facilitating electron relay from the donor $\mathrm{BH}_{4}{ }^{-}$to acceptor 4-NP to overcome the kinetic barrier. A characteristic absorption peak has been observed for pure $4-\mathrm{NP}$ at $317 \mathrm{~nm}$. The preliminary experiment revealed that the yellow color of 4-NP solution became deeper after the addition of $\mathrm{NaBH}_{4}$, and a red shift from 317 to $400 \mathrm{~nm}$ occurred due to the formation of 4-nitrophenolate ions [19]. In the absence of any catalyst, the peak at $400 \mathrm{~nm}$ remained unchanged even for several days and no reduction of 4$\mathrm{NP}$ was observed. In the presence of AgNPs and CuNPs as a catalyst, the yellow color of 4-NP solution gradually decreased and finally disappeared. In Figure 11, the UV-Vis absorption spectra revealed that the addition of AgNPs induced the lowering of peak intensity at $400 \mathrm{~nm}$ and the appearance of a new absorption peak at $293 \mathrm{~nm}$ indicating the formation of 4-aminophenol. Finally, the formation of 4AP is confirmed by the UV-Visible spectrum of pure 4-AP, which shows similar absorption peaks to that of an authentic sample. The complete disappearance of the $400 \mathrm{~nm}$ peak was observed within 30 minutes. In case of CuNPs, peak at $400 \mathrm{~nm}$ completely disappeared and a new peak was observed at $298 \mathrm{~nm}$ within 15 minutes. As compared to AgNPs, the CuNPs have better catalytic ability for the reduction of 4-NP. The rate constants of 4-NP were found to be $4.76 \times 10^{-2} \mathrm{~min}^{-1}$ with AgNPs and $7.5 \times 10^{-2} \mathrm{~min}^{-1}$ with CuNPs. Therefore, it is concluded that the CuNPs catalyze the reaction more than the AgNPs.

In case of 2-NP, the strong UV-Vis peaks appear at $352 \mathrm{~nm}$ and $279 \mathrm{~nm}$. The yellow color of 2-NP was discharged during the course of reduction under identical condition after the addition of $\mathrm{NaBH}_{4}$. It was found that there was a very slow decrease of absorbance during the chemical reaction without catalyst. However, after the addition of AgNPs, a decrease in the absorbance at $416 \mathrm{~nm}$ and shift of the peak from $279 \mathrm{~nm}$ to $285 \mathrm{~nm}$ with reaction time usually indicate steady reduction of 2-NP to 2-AP within 30 minutes (Figure 12). The CuNPs reduce 2 -NP to 2 -AP by sodium borohydride within 15 minutes. The kinetics of this reaction can be followed quantitatively by monitoring the change in the intensity of the peak at $400 \mathrm{~nm}$ with time. The reaction was carried out in excess concentration of $\mathrm{NaBH}_{4}$ as compared with that of nitrophenols (4-NP and 2-NP) and MNPs so the rate constant can be assumed to be independent of $\mathrm{NaBH}_{4}$ concentration. Hence, the reaction is considered as first-order kinetics with respect to nitrophenols concentration. The kinetics of the reaction can be represented using the equation

$$
\ln \frac{[A]}{\left[A_{o}\right]}=-k t
$$

where $k$ is first-order rate constant, $t$ is the reaction time, $\left[A_{o}\right]$ is the concentration of nitrophenols at time $t=0$, and $[A]$ is the concentration at time $t$. The value of $[A]$ can be obtained from the absorbance of the peak at $400 \mathrm{~nm}$. The rate constants $(k)$ can be calculated from the slope of the plot of $\ln$ $A / A_{o}$ versus reaction time (min). The rate constants of $2-\mathrm{NP}$ were found to be $2.44 \times 10^{-2} \mathrm{~min}^{-1}$ with AgNPs and $2.75 \times$ $10^{-2} \mathrm{~min}^{-1}$ with CuNPs.

The para isomer is absorbed at the longest wavelength with largest $\varepsilon_{\max }$ due to extended conjugation but ortho isomer is absorbed at the shorter wavelength with reduced $\varepsilon_{\max }$ due to intramolecular hydrogen bonding and steric interactions between the ortho substituents. Therefore, the reduction of 2-NP is slower than that of 4-NP.

\section{Conclusion}

A green method for the synthesis of $\mathrm{Ag}$ and $\mathrm{Cu}$ nanoparticles using leaves extract of $C$. occidentalis has been developed. The leaves of $C$. occidentalis are capable of producing silver and copper nanoparticles. The metal nanoparticles were characterized by UV-Vis, SEM- EDX, TEM, and XRD measurements. The formation of MNPs was observed by visible color change from yellow to brown and confirmed by UVVisible analysis. Crystalline nature of the nanoparticles is evident from sharp peaks in the XRD pattern. The biocapped AgNPs displayed higher antibacterial activity against $E$. coli and CuNPs more effectively against $S$. typhi. The CuNPs showed higher scavenging activity than AgNPs. The CuNPs have better catalytic ability for the reduction of 4-NP and 2NP than the AgNPs. The bioreduction process of the MNPs is an economic and ecofriendly simple one-step method. Green synthesized MNPs have various applications in biochemicalpharmacological investigations such as antimicrobial, antioxidant, anticancer, and wound healing activities. In addition, this green synthetic protocol would be a better alternative to the existing methods. 


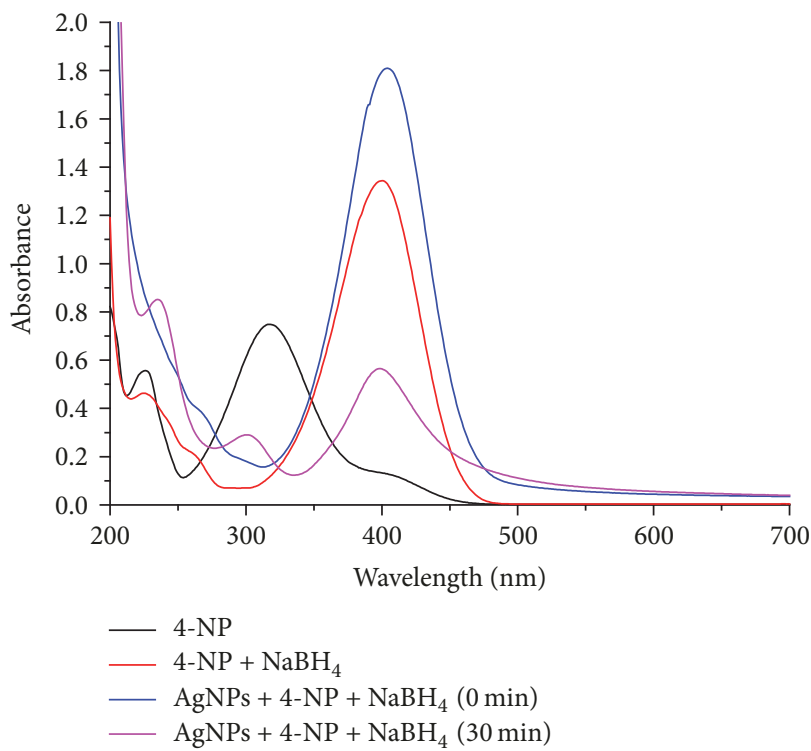

(a)

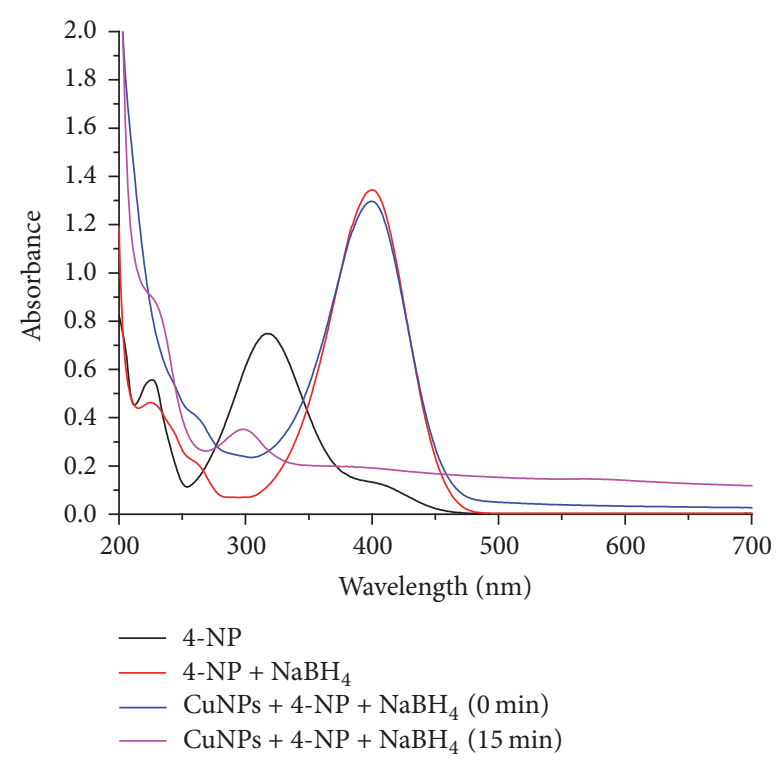

(b)

FIGURE 11: UV-Vis spectrum of the reduction of 4-NP by (a) AgNPs and (b) CuNPs of C. occidentalis.

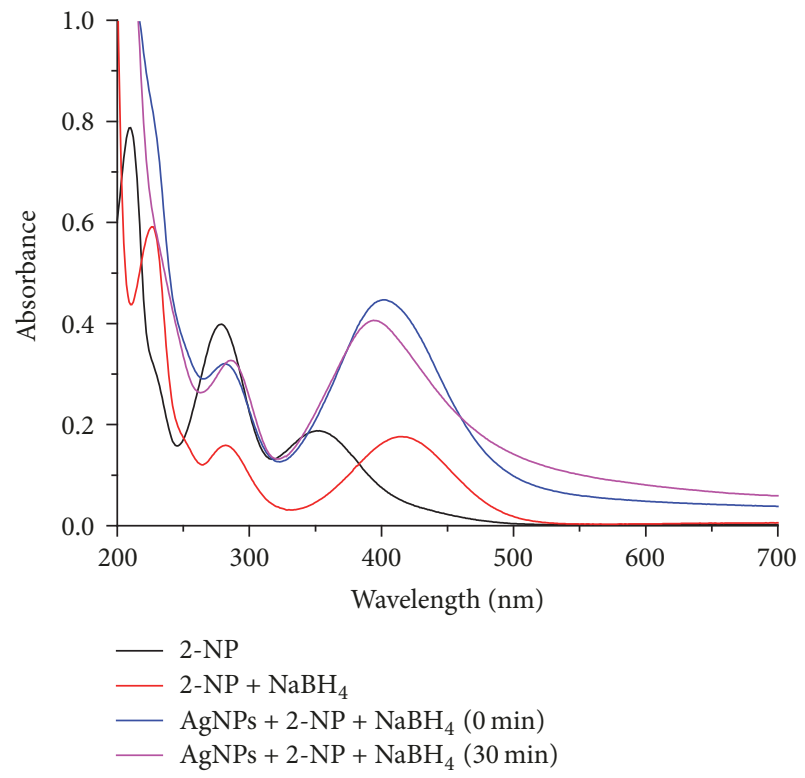

(a)

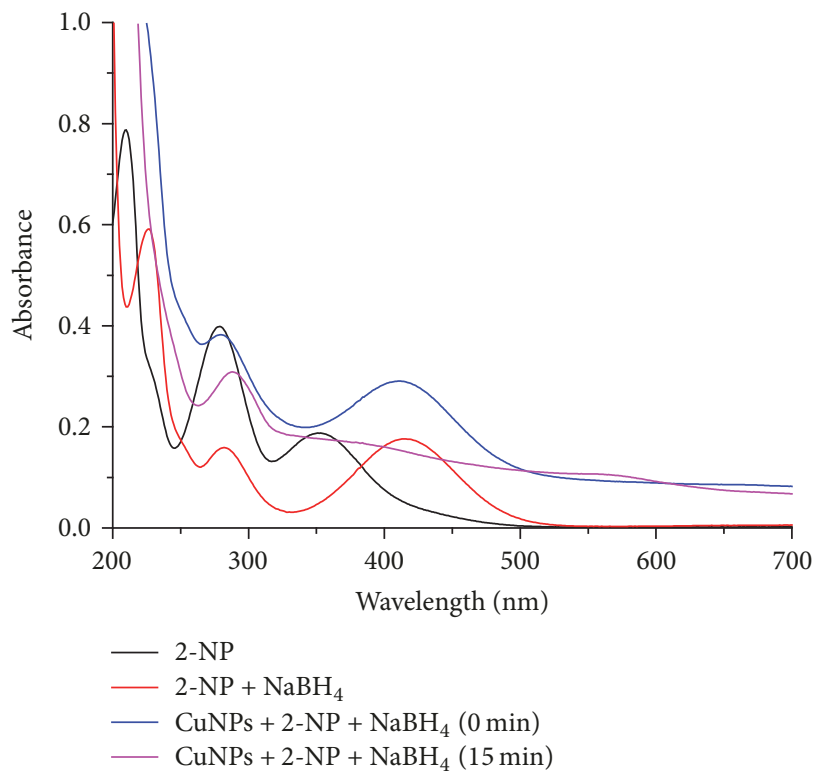

(b)

FIGURE 12: UV-Vis spectrum of the reduction of 2-NP by (a) AgNPs and (b) CuNPs of C. occidentalis.

\section{Conflicts of Interest}

The authors declare that they have no conflicts of interest.

\section{Acknowledgments}

The authors are thankful to the Department of Chemistry, Hemwati Nandan Bahuguna Garhwal University, Srinagar, Garhwal, Uttarakhand, India, for providing the laboratory facilities. The first author expresses her sincere thanks to UGC
New Delhi, India, Grant no. F1-17.1/2011-12/RGNF-SC-UTT6352/(SA-III/Website), for financial assistance. Thanks are due to UGC-DAE CSR, Indore, for TEM and SEM analysis.

\section{References}

[1] Z. M. Qi, H. S. Zhou, N. Matsuda et al., "Characterization of gold nanoparticles synthesized using sucrose by seeding formation in the solid phase and seeding growth in aqueous solution," The Journal of Physical Chemistry B, vol. 108, no. 22, pp. 7006-7011, 2004. 
[2] P. Mohanpuria, N. K. Rana, and S. K. Yadav, "Biosynthesis of nanoparticles: technological concepts and future applications," Journal of Nanoparticle Research, vol. 10, no. 3, pp. 507-517, 2008.

[3] K.-H. Cho, J.-E. Park, T. Osaka, and S.-G. Park, "The study of antimicrobial activity and preservative effects of nanosilver ingredient," Electrochimica Acta, vol. 51, no. 5, pp. 956-960, 2005.

[4] R. O. Becker, "Silver ions in the treatment of local infections," Metal-Based Drugs, vol. 6, no. 4-5, pp. 311-314, 1999.

[5] G. Borkow and J. Gabbay, "Copper, an ancient remedy returning to fight microbial, fungal and viral infections," Current Chemical Biology, vol. 3, no. 3, pp. 272-278, 2009.

[6] G. Borkow and J. Gabbay, "Putting copper into action: copperimpregnated products with potent biocidal activities," The FASEB Journal, vol. 18, no. 14, pp. 1728-1730, 2004.

[7] K. R. Krithikar and B. D. Basu, Cassia occidentalis Indian Medicinal Plants II edition, 1999.

[8] A. S. Saganuwan and M. L. Gulumbe, "Evaluation of in vitro antimicrobial activities and phytochemical constituents of Cassia occidentalis," in Proceedings of the Animal Reserarch International, vol. 3, pp. 566-569, 2006.

[9] V. Arya, S. Yadav, S. Kumar, and J. P. Yadav, "Antimicrobial activity of Cassiaoccidentalis L. (Leaf) against various Human Pathogenic Microbes," Life Sciences and Medicine Reserach, 1, p. 11, 2010.

[10] N. Sharma, P. Trikha, M. Athar, and S. Raisuddin, "In vitro inhibition of carcinogen-induced mutagenicity by Cassia occidentalis and Emblica officinalis," Drug and Chemical Toxicology, vol. 23, no. 3, pp. 477-484, 2000.

[11] J. P. Yadav, V. Arya, S. Yadav, M. Panghal, S. Kumar, and S. Dhankhar, "Cassia occidentalis L.: a review on its ethnobotany, phytochemical and pharmacological profile," Fitoterapia, vol. 81, no. 4, pp. 223-230, 2010.

[12] J. Lal and P. C. Gupta, "Two new anthraquinones from the seeds of Cassia occidentalis Linn," Experientia, vol. 30, no. 8, pp. 850851, 1974.

[13] R. Varshney, S. Bhadauria, and M. S. Gaur, "A review: Biological synthesis of silver and copper nanoparticles," Nano Biomedicine and Engineering, vol. 4, no. 2, pp. 99-106, 2012.

[14] T. N. V. K. Prasad and E. K. Elumalai, "Biofabrication of Ag nanoparticles using Moringa oleifera leaf extract and their antimicrobial activity," Asian Pacific Journal of Tropical Biomedicine, vol. 1, no. 6, pp. 439-442, 2011.

[15] S. Yallappa, J. Manjanna, M. A. Sindhe, N. D. Satyanarayan, S. N. Pramod, and K. Nagaraja, "Microwave assisted rapid synthesis and biological evaluation of stable copper nanoparticles using T. arjuna bark extract," Spectrochimica Acta Part A: Molecular and Biomolecular Spectroscopy, vol. 110, pp. 108-115, 2013.

[16] R. P. Samy and S. Ignacimuthu, "Antibacterial activity of some folklore medicinal plants used by tribals in Western Ghats of India," Journal of Ethnopharmacology, vol. 69, no. 1, pp. 63-71, 2000.

[17] G. Kapusetti, N. Misra, V. Singh, R. K. Kushwaha, and P. Maiti, "Bone cement/layered double hydroxide nanocomposites as potential biomaterials for joint implant," Journal of Biomedical Materials Research Part A, vol. 100, no. 12, pp. 3363-3373, 2012.

[18] S. S. Shankar, A. Ahmad, and M. Sastry, "Geranium leaf assisted biosynthesis of silver nanoparticles," Biotechnology Progress, vol. 19, no. 6, pp. 1627-1631, 2003.

[19] N. Pradhan, A. Pal, and T. Pal, "Silver nanoparticle catalyzed reduction of aromatic nitro compounds," Colloids and Surfaces A: Physicochemical and Engineering Aspects, vol. 196, no. 2-3, pp. 247-257, 2002.
[20] J. J. Mock, M. Barbic, D. R. Smith, D. A. Schultz, and S. Schultz, "Localized surface plasmon resonance effects by naturally occurring Chinese yam particles," The Journal of Chemical Physics, vol. 116, no. 15, pp. 6755-6759, 2002.

[21] R. Sathyavathi, M. B. Krishna, S. V. Rao, R. Saritha, and D. Narayana Rao, "Biosynthesis of silver Nanoparticles using Coriandrum Sativum leaf extract and their application in nonlinear optics," Advanced Science Letters, vol. 3, no. 2, pp. 138-143, 2010.

[22] S. H. Syed, S. Singh, R. Y. Parikh et al., "Bacterial synthesis of copper/copper oxide nanoparticles," Journal of Nanoscience and Nanotechnology, vol. 8, no. 6, pp. 3191-3196, 2008.

[23] J. Y. Song, H.-K. Jang, and B. S. Kim, "Biological synthesis of gold nanoparticles using Magnolia kobus and Diopyros kaki leaf extracts," Process Biochemistry, vol. 44, no. 10, pp. 1133-1138, 2009.

[24] H. Susanto, Y. Feng, and M. Ulbricht, "Fouling behavior of aqueous solutions of polyphenolic compounds during ultrafiltration," Journal of Food Engineering, vol. 91, no. 2, pp. 333-340, 2009.

[25] H. Bar, D. K. Bhui, G. P. Sahoo, P. Sarkar, S. Pyne, and A. Misra, "Green synthesis of silver nanoparticles using seed extract of Jatropha curcas," Colloids and Surfaces A: Physicochemical and Engineering Aspects, vol. 348, no. 1-3, pp. 212-216, 2009.

[26] T. Theivasanthi and M. Alagar, "Electrolytic synthesis and characterization of silver nanopowder," Nano Biomedicine and Engineering, vol. 4, no. 2, pp. 58-65, 2012.

[27] B. D. Cullity, Elements of X-ray Diffraction, Addison-Wesley Publishing Company, Inc. USA, 1978.

[28] R. John and S. Sasi Florence, "Structural and optical properties of $\mathrm{ZnS}$ nanoparticles synthesized by solid state reaction method," Chalcogenide Letters, vol. 6, no. 10, pp. 535-539, 2009.

[29] L. Nicholas, S. Ansari, F. R. Livens, J. C. Renshaw, and J. R. Lloyd, "Formation of nanoscale elemental silver particles via enzymatic reduction by Geobacter sulfurreducens," Applied and Environmental Microbiology, vol. 74, no. 22, pp. 7090-7093, 2008.

[30] K. S. Hwan, L. Hyeong-Seon, R. Deok-Seon, C. Soo-Jae, and L. Dong-Seok, "Antibacterial activity of silver-nanoparticles against Staphylococcus aureusand Escherichia coli," Korean Journal of Microbiology and Biotechnology, vol. 39, no. 1, pp. 77-85, 2011.

[31] A. Shirley and B. G. Dastager, "Antimicrobial activity of silver nanoparticles synthesized from novel Streptomycesspecies," Digest Journal of Nanomaterials and Biostructers, vol. 5, no. 2, pp. 447-451, 2011.

[32] M. Valodkar, S. Modi, A. Pal, and S. Thakore, "Synthesis and anti-bacterial activity of $\mathrm{Cu}, \mathrm{Ag}$ and $\mathrm{Cu}-\mathrm{Ag}$ alloy nanoparticles: a green approach," Materials Research Bulletin, vol. 46, no. 3, pp. 384-389, 2011.

[33] J. Autian, "Polymer Science and Technolog," Polymers in Medicine and Surgery, vol. 8, p. 181, 1975.

[34] H. Y. Lin and C.-C. Chou, "Antioxidative activities of watersoluble disaccharide chitosan derivatives," Food Research International, vol. 37, no. 9, pp. 883-889, 2004.

[35] K. Kuroda, T. Ishida, and M. Haruta, "Reduction of 4-nitrophenol to 4-aminophenol over Au nanoparticles deposited on PMMA," Journal of Molecular Catalysis A: Chemical, vol. 298, no. 1-2, pp. 7-11, 2009. 


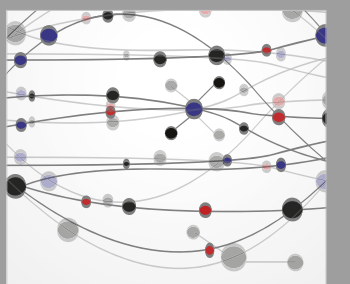

The Scientific World Journal
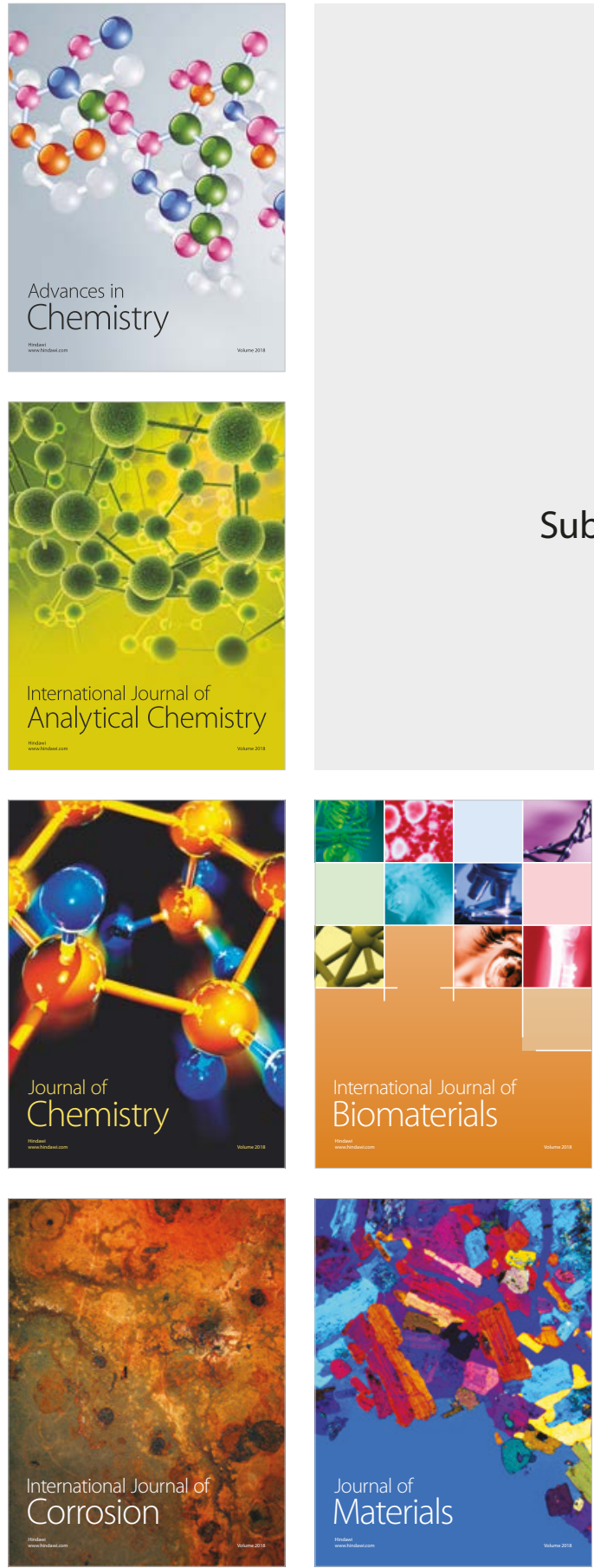

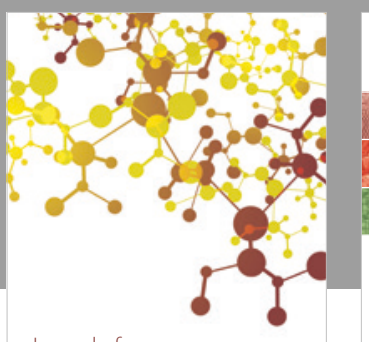

Journal of

Applied Chemistry
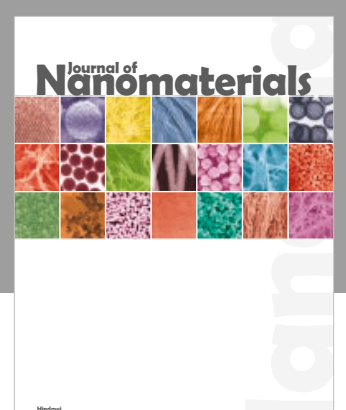

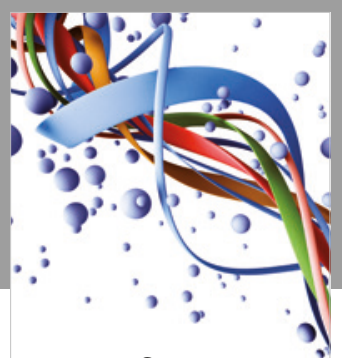

Scientifica

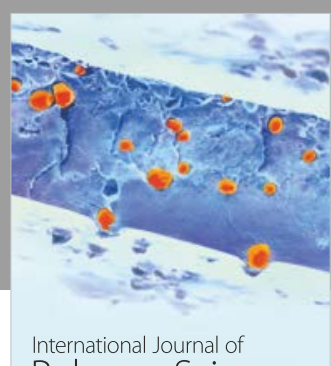

Polymer Science

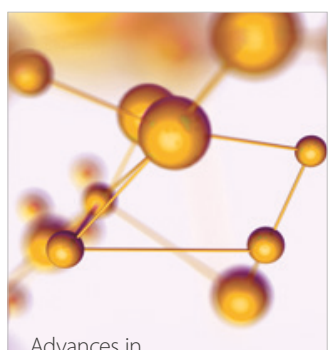

Physical Chemistry
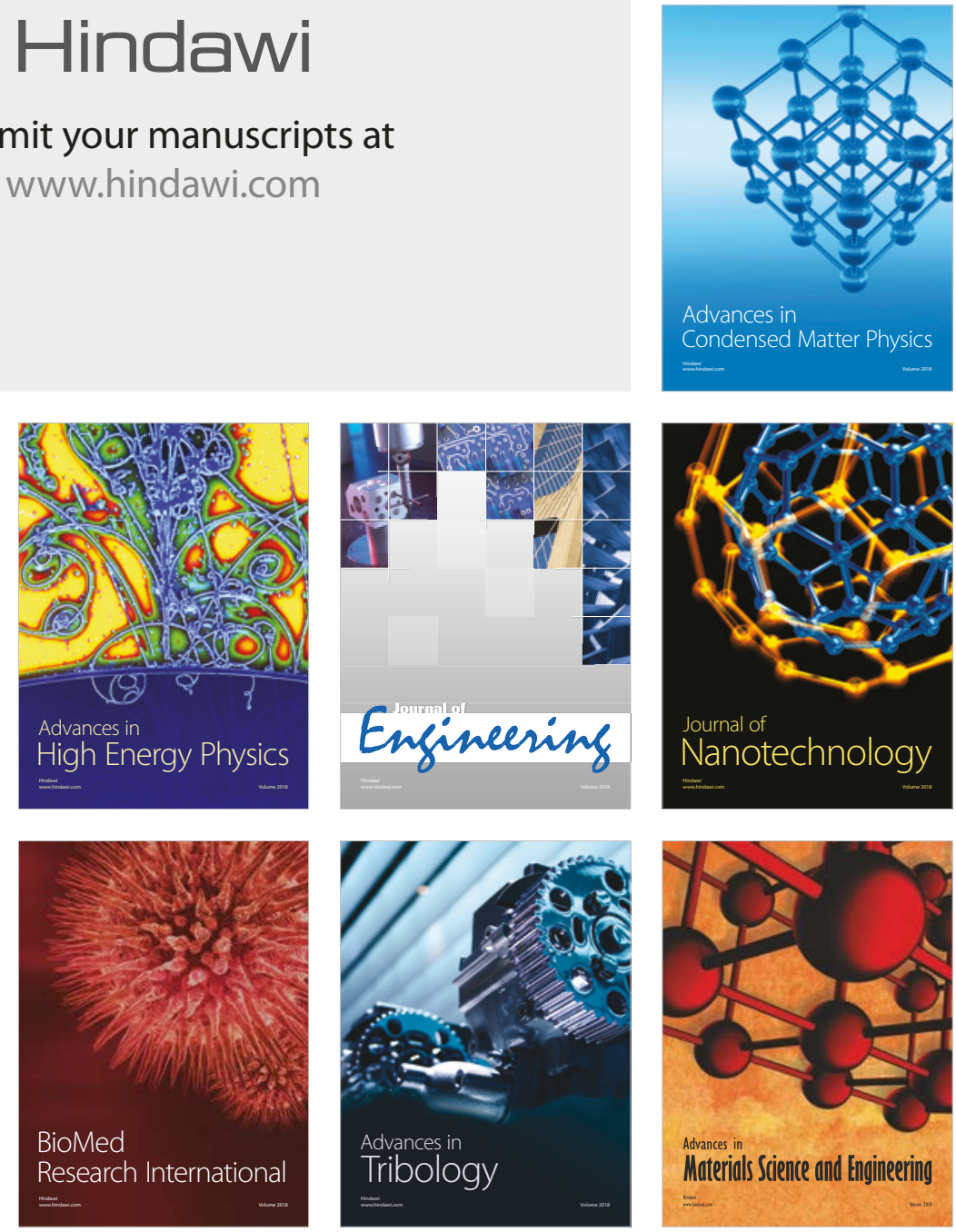